\title{
An Analysis of the Conceptual Features of Contemporary Public Art and Its Application in Colleges and Universities
}

\author{
Liu Xiaofei \\ School of Arts, Xi'an University, 710065
}

Keywords: Public Art; Modern City; Geographical Space; Conceptual Features

\begin{abstract}
The development of art is accompanied by the constant exchange of identity between "art noumenon" and "artistic social responsibility theory". It has always responded to different needs of art in different times. Modernism in the last century brought the art form to extremes. Then there was a shift in the direction of art to social and political themes. As one of the important forms of contemporary art, public art has gradually shifted its focus to a wider range of popular societies and public spheres. It emphasizes the connection between art and city, life and the public, breaks the boundaries between art and various fields, and has far-reaching significance for the development and propaganda of cities. In the teaching content and objectives of contemporary public art teaching in colleges and universities, teachers should also deeply understand the nature of public art education. The concept of contemporary public art is implemented into art teaching, and teachers actively innovate and truly play the leading role of college public art in practical exploration in teaching theory.
\end{abstract}

\section{The Meaning of Contemporary Public Art and Its Relationship with Modern City}

The development of modern art has allowed art to embark on the road of ideas quickly. From the last century, the plastic arts, including painting and sculpture, have gradually become divorced from the existing relationship between itself and the art carrier and have moved toward pluralism and human culture. With the double development of science and technology and contemporary art, contemporary public art has played a multi-factor conceivable and collective concept in a modern city. In the popular and public art form, the concept and spirit of each level are communicated to the public. Contemporary public art infiltrates into modern life in various artistic forms. It often carries the history and culture of a city with its representative identity of modern urban civilization. And with its distinctive or innovative artistic qualities, it has established a highly recognizable image for the city and its people. It is a product of contemporary society in terms of material and ideological foundations. At present, the common use of public artworks in the country should prove a common phenomenon, that is, "the content is greater than the form." That is to say, public artworks are often created for the purpose of "utility", and they bear a huge social responsibility when they are created. Generally speaking, for most of the city's public buildings or sculptures, it does not have the liberty of the architecture itself and the sculpture itself rather than to serve the propaganda meaning of a certain city. Amnesty uses metaphors and symbols to give public art works a meaning that caters to geographical themes.

\section{Conceptual Features of Public Art}

Public art is, on one level, an artistic creation activity based on the needs of the city or the public. It contains the basic elements of the conceptual creation of the main body of art, the public space as a carrier and the interaction and participation of the general public. Neither can it depart from the development of art history to see its changing trends, nor can it be simply classified as a school or style. As a product of ideology, contemporary public art has certain social attributes and creators' artistic ideas. Its core is not only for the aesthetic issues of public space, but more importantly, it is directed at the issue of power in the public space and its subsidiary significance. The following sections will discuss the conceptual features of contemporary public art in modern cities.

Publicity and Interaction. As a special carrier of public art creation, public space determines the 
most common nature of public art, namely publicity. From a certain perspective, publicity is an important criterion for distinguishing public art and urban sculpture. The two are neither affiliated nor parallel. Urban sculpture is only one of its many realization ways for public art. Public art can realize its publicity by means of urban sculpture. Besides, this public nature also promotes the interaction between public art and the viewer because of the political and social nature of public space. Interaction is an extension of public art and it is also an integral part of public art. The interaction between the audience and the work is mainly reflected in the audience's reaction and feedback to the work, and the result does not have absolute stability and predictability. In this interactive process, the value of public art works can only be completed in the end.

Symbolism and Humanism. Generally speaking, public art does not only assume the responsibility of beautifying the environment and decorating space. The development of contemporary art has long been difficult to separate from sociology, politics and even philosophy. As one of the expressions of contemporary art, public art often makes the sociology of the work itself superior to art. After the 85th trend of the last century, the boundaries between art and life, politics, and others were blurred. The first example is Xu Beihong, who advocated the application of social realism in the field of painting in a special social context. Until the 1980s and 1990s, artists directly used the finished materials of the Cultural Revolution to express their own political views. In terms of public art, as one of the forms of contemporary art, its important creative resources come from sociology. In the field of public art, social values often exceed artistic values. The commonality surpasses the individuality, and the public's perception transcends the individual's notion of artists, thus more exemplifying the phenomenon and trend of the transition from public art to sociology.

For example, Ordos City's "Scorpio Sky", "Lucky Sullard", "Golden Triangle", "Half Day Flower" and other representative public works of art, most of these buildings or sculptures were built with strong purpose and symbolism from the beginning. Most of their construction time was concentrated around the year 2000, and Erdos was renamed Ordos in 2001 when it was one of the 18 typical regions in the 30 years of reform and opening up. With support, it has rapidly achieved economic development by relying on the rich underground resources and other areas of resources. These works are precisely to conform to the theme of this era, and they all confirm the positive atmosphere of "advancing with the times" . In other words, it exists as a symbol of "representing the cultural characteristics of the nation" and not as an artwork itself.

Geographical Targeted and Timeliness. Public art is not universal. It is for the specific space, specific cities, specific areas and places to respond to the development and status of the entire city. That is to say, as a public art, urban architecture and sculpture must be coordinated with this particular space, and should be set against the overall level of political, economic and cultural development of the city. Take the urban sculpture as an example, most urban sculptures record the history and stories of the city, making it a specific area and place of particular charm. For example, the Shaanxi Ankang Museum, whose predecessor was the Ankang Historical Museum, and its historical duration is not long enough to be built in response to the development of local cities. The

"three main floors of the building and six local floors reflect the characteristics of 'high-level riversides and all-encompassing areas" ". And "the exhibition is composed of 'three main and two auxiliary', namely, ' Tianfu Ankang', 'Maiyuan Ankang' and 'Zhumeng Ankang' three basic exhibitions and 'Ankang three-line construction process exhibition' and 'collection of painting and calligraphy boutique'. The thematic exhibitions also systematically demonstrated Ankang's "Special Resources", “Humanities and History”, "Major Events”, “Glorious Achievements” and "Future Plans", and outlined the past, present and future of Ankang, truly playing the function of “Ankang Cultural Ancestral Hall” and "Ankang meeting room”. Strictly speaking, China does not have a traditional urban sculpture. The current garden monuments and contemporary urban public art also have different starting points. This form has been influenced by Europe and the United States to a certain extent. For many European cities, the public artwork of the city is the "identity card" of the city. For example, the "pissing boy" in Belgium' s capital Brussels and the bronze statue of the "Little Mermaid" in Copenhagen, Denmark, these two places greatly 
emphasize the specificity of the regions and places. After years of dialogue with city dwellers, they have long since become an embodiment of the city's soul. From this point of view, public art has a certain amount of time. Through continuous "exchanges" between the work and the city, the artistic charm of the work itself is increasingly reflected.

\section{The Application of Conceptual Features of Contemporary Public Art in College Teaching}

As a kind of many kinds of art forms, public art plays an important role in contemporary art, and it is also an indispensable part of "aesthetic education" in the process of cultivating talents in universities. It has an imperceptible influence on students' artistic quality education. It not only can develop students' innovative thinking, but also enables students to recognize the relationship between art and life, politics, society and self. Therefore, it is urgently need to comprehensively promote the application of public art in college teaching and solve the difficult development of public art education in colleges and universities in the new era. Colleges and universities should coordinate the distinctive concept of public art and realize the positive interaction between public art education and learners of virtue. The following is a further explanation of the application of the concept of contemporary public art in teaching.

Spread the Concept of Public Art While Improving the Teaching System. Since art forms such as conceptual art and installation art have become popular, more and more art academies have successively established public art or related disciplines and professions. However, in terms of teaching content, most of them still follow the techniques and forms of traditional plastic arts, or simply increase the scale of the art works and obtain the viewer's embarrassment in terms of quantity or volume and material changes. In fact, this still remains at the level of the art form, but public art is not merely an educational issue related to skills and styles, but an education aimed at exploiting the needs of the public art and cultural life of emerging urban forms and modern civil society. Since most of the public arts teaching is still lacking in the comprehensive application of disciplines and sociology, anthropology, urban studies and communications, it is impossible for most students to acquire comprehensive capabilities that span the range of specialized technologies. It is difficult to organically combine artistic skills with various fields as students lack the relevant knowledge, ideas and method systems required by professionals, and also lack awareness, humanistic quality and social responsibility of Chinese public art construction. Therefore, teachers should thoroughly implement the concept of contemporary public art in teaching, and deepen the concept of public art publicity and interaction, symbolism and humanism, regional pertinence and timeliness into teaching content. Students are deeply aware of the conceptual features of public art and their important role in urban construction and they are also used flexibly in their creation. The basic purpose of public art is to enable more social citizens, that is, ordinary people to care about and join in the creation and sharing of the art culture related to the big family of society and the management of public utilities, making our society's public life and public environment more democratic, colorful and beautiful.

Innovate Among Existing Public Art Ideas. As early as the impact of Pop Art, the boundaries between art and life have been broken, and life has an important creative meaning for art. In the teaching of art, if teachers stick too much to the textbooks and get out of our lives, art can not express life perfectly. The public art teaching activities only realize the combination of theoretical knowledge and real life, and continue to innovate the theory in light of changes in the times, so as to find the foundation of reality for the students' teaching materials and improve and nurture students' creativity. Therefore, in the teaching of public art in colleges and universities, teachers not only must thoroughly implement the basic concept of public art, but also do some innovative research based on this concept. According to changes in the times, social development and the people's psychological needs and reforms, integrate the knowledge in multiple fields perfectly. In order to realize the innovation of the public art concept, colleges and universities should encourage teachers and students to step out of the constraints of teaching materials, go deep into major cultural institutions, people's daily life and urban construction and explore the innovation of artistic concepts through social and artistic practice. Then teachers can take the initiative to participate in 
the beauty, and actively create a complete concept of beauty and a harmonious development of the body and mind, to help students open up a treasure trove of endless artistic resources for their lifetime artistic appreciation.

\section{Conclusion}

Contemporary public art plays an important role in the field of modern urban construction. It is not only a part of the urban composition, but also has its own unique concept nature. For example, publicity and interaction, symbolism and humanism, geographically targeted and timeliness and other exchanges with the city, all of them are the symbols of urban history and culture. and is a symbol of urban history and culture. With the increasingly widespread application of this discipline, the use and development of contemporary public art in college teaching is very important. It is not only categorized into the category of art noumenon and language and a beautification factor of public space, but is a synthesis of subjects in various fields such as social culture and public management. Therefore, in related teaching, colleges and universities should pay attention to teaching the notable concept of contemporary public art in depth, and on this basis, carry out innovative research on it to make it develop together with the times and the city. Whether in the development or teaching of public art, artists, educators and the general public all need to make continuous efforts to grasp the cultural and historical roots of the city and gradually improve and perfect the ideas of the art system and the art concept.

\section{Reference}

[1] H. Y. Wang. Introduction to Public Art. China Academy of Fine Art Press. 2007.

[2] X. Q. He. Public Art and Urban Space Construction. China Building Industry Press. 2013.

[3] H. Wang. Public Art Creative Design. Tianjin University Press. 2013.

[4] H. Wang. Design and Humanities - Contemporary Public Art. Tianjin University Press. 2015.

[5] Z. H. Zhao. Contemporary Public Art Research. Commercial Press. 2015.

[6] J. Zhang. Public Art (Music). Electronic Industry Press. 2016.

[7] X. S. Chen. European Urban Public Art. Mechanical Industry Press. 2012.

[8] Y. S. Wang. Public Art Design. China Building Material Industry Press. 2011.

[9] Y. C. Wang. Art Publicity: Research on Art Publicity. Peking University Press. 2016.

[10] French Yi Xi Culture. French Public Art. Liaoning Science and Technology Press. 2008. 